\title{
REVITALIZAÇÃO URBANA, PATRIMÔNIO E MEMÓRIAS NO RIO DE JANEIRO: USOS E APROPRIAÇÕES DO CAIS DO VALONGO
}

\author{
Urban revitalization, heritage and memories in Rio de \\ Janeiro: uses and appropriation of Valongo Wharf
}

\section{MÁrcia leitÃo Pinheiro e SANDra SÁ CARneiro}

Márcia Leitão Pinheiro é mestre em Ciências Sociais pela UERJ e doutora em Ciências Humanas (Antropologia Cultural) pela UFRJ. É professora associada e pesquisadora do Laboratório de Estudos da Sociedade Civil e do Estado da Universidade Estadual do Norte Fluminense Darcy Ribeiro (UENF), membro do Diretório Nacional de Pesquisa Arte, Cultura e Poder, pesquisadora associada do Museu Afro Digital do Rio de Janeiro (UERJ) e do Programa de Estudos e Debates dos Povos Africanos e Afro-Americanos (Proafro/UERJ), e professora visitante no Instituto de Estudos Sociais e Políticos (IESP) da UERJ (marcialpx@hotmail.com).

Sandra de Sá Carneiro é mestre em Antropologia Social pelo PPGAS/Museu Nacional/UFRJ e doutora em Antropologia pelo Programa de Pós-Graduação em Sociologia e Antropologia da UFRJ, com pós-doutorado em Antropologia na Universidade de Santiago de Compostela, Espanha. É professora adjunta e pesquisadora do Programa de Pós-Graduação em Ciências Sociais do Instituto de Ciências Sociais da UERJ, procientista da UERJ/ FAPERJ e pesquisadora do CNPq (sandrasacarneiro@ uol.com.br).

Artigo recebido em 29 de janeiro e aprovado para publicação em 21 de março de 2016. 


\title{
RESUMO
}

0 objetivo deste artigo é analisar os diferentes usos e apropriações que o Cais do Valongo, antigo local de desembarque de escravos, vem sofrendo no seu processo de patrimonialização, iniciado com a sua "redescoberta" em 2011, durante as obras de revitalização da Zona Portuária do Rio de Janeiro. Discutimos ainda como outras vozes, outros usos do patrimônio e, por conseguinte, outras memórias estão em permanente negociação com a apropriação do local por segmentos do Movimento Negro. 0 artigo resulta da leitura de materiais de divulgação do projeto de revitalização, de registro videográfico e da realização de etnografia.

PALAVRAS-CHAVE: revitalização, patrimônio, memória, apropriação, herança africana.

\begin{abstract}
The purpose of this paper is to analyze the different uses and appropriations that the Valongo Wharf, ancient area where slaves disembarked in Rio de Janeiro, has been suffering during its transformation into "cultural heritage". This process started with the wharf's "rediscovery" in 2011, during the revitalization works in the city's historic Port Area. We discuss how other voices, other uses of the heritage, and thus other memories are in permanent negotiation with the appropriation of the area by segments of the Black Movement. The paper was based in the material about the revitalization that has been distributed, as well as videographic registration and ethnographic material.
\end{abstract}

KeYwords: revitalization, heritage, memory, appropriation, African heritage.

\section{RÉSUMÉ}

Le présent article s'attache à analyser les différents usages et appropriations que subit l'ancien site du Quai du Valongo, lieu de débarquement des esclaves, dans le cadre de sa patrimonialisation, qui démarre avec sa "redécouverte" en 2011, pendant les travaux de réhabilitation du secteur portuaire de Rio de Janeiro. On discutera aussi la façon dont d'autres voix, d'autres utilisations du patrimoine et, par conséquent d'autres mémoires sont en négociation permanente avec l'appropriation des lieux par des segments du Mouvement Noir. L'article est le fruit de la lecture du matériel de divulgation du projet de réhabilitation, d'enregistrements en vidéo et de la réalisation d'une ethnographie.

MoTS-CLÉS: revitalisation, patrimoine, mémoire, appropriation, héritage africain. 
este artigo, buscamos analisar os diferentes usos e apropriações que o Cais do Valongo, antigo local de desembarque de escravos, vem sofrendo no seu processo de patrimonialização, iniciado com a sua "redescoberta" ou "desenterramento" em 2011, durante as obras de revitalização da Zona Portuária do Rio de Janeiro. A discussão deste tema é relevante porque permite evidenciar como um lugar pode ser vinculado a diferentes discursos econômicos, políticos e sociais. E também por revelar, no diálogo com o processo de intervenção urbanística em curso, como a noção de patrimônio pode figurar como matéria-prima na transformação da imagem da cidade. Estas questões ganham novos contornos, como nos lembram Leite e Peixoto (2009) e Arantes (2002), particularmente no contexto de determinadas políticas urbanas, quando estas estão associadas a uma noção de espaço público que pode ser potencializado como atração turística. Trata-se de considerar, como bem observam Leite e Peixoto (2009: 94), a intervenção como processo com relevantes implicações na infraestrutura urbana, na sua arquitetura e também na "formatação dos usos dos espaços enobrecidos".

Sabemos que um dos efeitos de uma intervenção urbana pode ser a apresentação de um espaço público asséptico, que passa a ser definido a partir das ideias de ordem e disciplina, com o uso de determinados dispositivos para dirimir tensões e conflitos, que podem ser vistos como desordem. Com isto temos a construção de uma imagem de cidade cujo passado não pode deixar de ser reinventado como parte do exercício do projeto de urbanização a ser materializado, como podemos compreender a partir das colocações de Sharon Zukin (Frugoli Jr e Talhari, 2014). Nesse quadro, o patrimônio também é afetado, ainda que ele possa encarnar algo comum e definidor de uma nacionalidade. No entanto, a proximidade entre poder público e empresas o leva a ser reelaborado e considerado viável de sustentação se transformado em atração turística (Leite, 2007). Assim, observamos que o patrimônio não está ileso dos conflitos e tensões, apesar da imagem de ordem que pauta os projetos de revitalização, porque existem as reivindicações de diferentes setores da sociedade que buscam sua expressão e visibilidade. Por isso, o patrimônio pode ser entendido como espaço de "luta material ou simbólica" (Canclini, 1997:195), envolto em disputas, reformulações e conflitos.

Quando falamos em patrimônio, entendemos que ele: a) é uma elaboração que compreende uma modalidade de memória que caracteriza um grupo social; b) é uma categoria que apresenta diferentes acepções, e por isso torna-se adequado contemplar as concepções em vigor 
no meio pesquisado; c) é uma construção social passível de ser percebida por meio de códigos sensíveis; d) está relacionado às experiências de seus formuladores e usuários, podendo ser por estes percebido, usado, transformado ou destruído; e) é definido a partir de vasta rede de relações sociais, culturais e econômicas. Estas indicações seguem as pistas analíticas defendidas por autores como Gonçalves (2013), Leite e Peixoto (2009), Leite (2007) e Canclini (1997).

Dividimos o presente artigo em quatro partes. Na primeira, apresentamos uma contextualização da zona portuária e do projeto de revitalização em curso. Na segunda, fazemos um histórico e buscamos mostrar como o Cais do Valongo, um dos lugares que integram o Circuito Histórico e Arqueológico de Celebração da Herança Africana (Circuito da Celebração Africana), antes ocultado e invisível, passou a ter valor patrimonial e a integrar a revitalização. Na terceira parte, procuramos problematizar como o patrimônio pode ser entendido como um espaço adequado à inscrição da memória de um grupo social. Neste item, nosso material de pesquisa foi construído a partir da análise de dois casos empíricos - a celebração do "centenário de Abdias do Nascimento" e o evento "Herança Africana - intervenções urbanas no caminho do Porto", ambos realizados em 2014 no Cais do Valongo. Nosso interesse é explorar as concepções nativas da categoria patrimônio, como sugerido por Gonçalves (2013), entendendo-a também como imagem da vida na cidade (Canclini, 1999; Proença e Peixoto, 2008). Na quarta e última parte, refletimos sobre outras vozes, outros usos do patrimônio e, por conseguinte, outras memórias, que estão em conflito e em negociação (Macé, 2012).

Cumpre ressaltar que durante dois anos procuramos, através da observação participante, acompanhar diversas atividades e práticas desenvolvidas no Cais do Valongo, elaborando etnografias de cada situação investigada, como os dois eventos acima citados, que estão mais diretamente relacionados aos temas aqui tratados. Também foram utilizados documentos e matérias veiculados pela Companhia de Desenvolvimento Urbano da Região do Porto do Rio de Janeiro (Cdurp), gestora da prefeitura na Operação Urbana Consorciada Porto Maravilha, disponibilizados na sua Revista Porto Maravilha, no site e no blog da empresa. Relacionamos ainda vídeo e materiais de divulgação das celebrações enfocadas, pois entendemos que eles viabilizam lidar com práticas e discursos que veiculam atos, ideias, significados e concepções pertinentes ao tema investigado.

\section{ZONA PORTUÁRIA: PATRIMÔNIO E REVITALIZAÇÃO}

Zona Portuária conta com quatro bairros - Caju, Gamboa, Saúde e Santo Cristo -,
formando parte do centro antigo da cidade. Ela está relacionada à produção cultural de afro-brasileiros e é reconhecida por sua relevância cultural para a cidade, sendo apontada 
a Pedra do Sal, no Morro da Conceição, como reduto do samba, do choro, berço do carnaval carioca e das festas de santos do candomblé (Mattos e Abreu, 2007). Mas somente em 1987 o valor histórico e cultural desse local passou a ser oficialmente reconhecido e tombado como marco representativo da africanidade na cidade, por sua ligação histórica com os escravos e importância para os adeptos das religiões de matriz africana. ${ }^{1}$

Em 1983, o antigo Serviço do Patrimônio Histórico e Artístico Nacional (SPHAN) voltou-se para o Morro da Conceição e seu entorno, que contava com dez monumentos já tombados, a fim de proteger cerca de 1.200 edificações (SPHAN, 1983). A partir da mobilização popular diante de condições precárias de prédios históricos presentes na região, em 1988, a prefeitura da cidade reconheceu, como Área de Proteção ao Ambiente Cultural (APAC), locais existentes nos bairros da Saúde, Gamboa e Santo Cristo.

Em 2011, com as obras de escavações, apareceram os sinais do Cais da Imperatriz sob o qual estava o Cais do Valongo, que passou a ser o lugar-chave para a elaboração do Circuito da Celebração Africana. Tem sido dito que ele foi "encontrado", como se fosse por acaso, mas sua localização não era desconhecida por pesquisadores. Há na Praça Jornal do Comércio, situada na avenida Barão de Tefé, um obelisco no qual consta uma placa com a indicação de que no subsolo estaria o antigo cais. Cabe explicitar que o ato de "desenterrar" o Cais do Valongo não constava do planejamento inicial. Mas a intervenção no subsolo provocou pesquisadores atentos à necessidade de monitoramento especializado de possíveis sítios arqueológicos, conforme a legislação do Instituto do Patrimônio Histórico e Artístico Nacional (IPHAN).

0 processo de revitalização denominado "Porto Maravilha" é considerado uma das maiores propostas de transformar a paisagem da Zona Portuária do Rio de Janeiro. Em diálogo com o que foi realizado em cidades portuárias (Arantes, 2002; Giacomet, 2008), a revitalização integra e expressa, para a prefeitura do Rio de Janeiro, uma iniciativa econômica com a finalidade de valorizar parte do centro histórico da cidade.

A partir de uma parceria público-privada, em curso desde 2010, o plano de infraestrutura engloba a transformação do sistema viário da região, investimentos em saneamento básico, telecomunicações, reforma de edificações e construção de espaços museais. 0 projeto é realizado pela Companhia de Desenvolvimento Urbano da Região do Porto do Rio de Janeiro (Cdurp), criada pela Lei Complementar 101/2009. Essa companhia tem por missão articular ações para fazer da região algo moderno (Cdurp, 2011) e, para tanto, efetua a articulação entre empresas e órgãos públicos.

Para conduzir o planejamento, a companhia desenvolve uma atuação econômica e política, viabilizando a alteração da Área Especial de Interesse Urbanístico (AEIU), que perfaz 
5 milhões de metros quadrados, anteriormente definida pela prefeitura. A Cdurp destaca que as ações de revitalização são asseguradas com a negociação dos Certificados de Potencial Adicional de Construção (Cepacs) e são apontadas como uma eficiente ferramenta para a renovação urbana e a geração de renda a ser aplicada na área delimitada pelo projeto. Em geral, a emissão dos títulos é realizada pelo poder público e controlada pela Comissão de Valores Imobiliários (CVI), sendo utilizada por governos que buscam otimizar o fluxo de caixa (Brugugnoli, 2012). 0 investidor, ao adquirir Cepacs, passa a ter condições para iniciar edificações ou ampliar sua área de construção. Contudo, esse instrumento tem sido questionado no que toca à diminuição de desigualdades, uma vez que poderá proporcionar, inevitavelmente, benefício ao setor privado (Ferreira e Fix, 2001).

0 projeto de revitalização ainda compreende um eixo cultural, sendo previstos o incentivo à prática de negócios e a produção de emprego. Isto está relacionado à recuperação e valorização do patrimônio material, à preservação da memória da região e ao incentivo de expressões artísticas e culturais. Tem sido dito que para atingir esses objetivos a prefeitura da cidade destina somente $3 \%$ dos recursos provenientes da negociação dos Cepacs. Por sua vez, o "patrimônio cultural e artístico" é apontado como algo viável para tornar a região atraente economicamente, conforme os "princípios de sustentabilidade" e "inclusão e desenvolvimento social", como divulgado pela Cdurp (2011:5). Desse modo, apesar de a cultura receber menor porcentagem com a negociação dos Cepacs, ela é vista como conveniente para um empreendimento econômico. Em outras palavras, a cultura e o patrimônio são apreciados pelo ângulo da rentabilidade e passam a fazer parte do "universo dos negócios", sendo isso possível com a produção de políticas culturais que atendam à revitalização, nada estranho às práticas similares efetivadas globalmente (Arantes, 2002: 31).

Não podemos minimizar nem os diferentes impactos, nem os custos sociais desse projeto de transformação da cidade que foi aprovado pela Câmara Municipal do Rio de Janeiro sem maiores discussões e que tem sido objeto de vários questionamentos e críticas, tanto do ponto de vista urbanístico, quanto de seus efeitos para os moradores da região afetados mais diretamente. $^{2}$

\section{UM BREVE HISTÓRICO SOBRE O CAIS DO VALONGO}

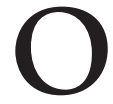

Cais do Valongo teve relevância para a economia da cidade, pois foi utilizado por embarcações que transportavam mercadorias e seres humanos oriundos de países africanos e tornados escravos. Seu surgimento se deu nos primeiros anos de 1800, com a transferência da atividade portuária do Cais Central, localizado próximo ao Paço da Cidade 
(Honorato, 2011), e sua atividade se estendeu até 1831, ano de promulgação da lei que coibia a entrada de africanos no país na condição de escravos - embora a atividade tenha continuado com o uso de lugares clandestinos para incrementar o trabalho nas fazendas no interior do estado (Yabeta e Gomes, 2013). Em 1843, o local foi aterrado para que surgisse o Cais da Imperatriz, construído para o desembarque da futura esposa de D. Pedro II. Mais tarde, esse cais também foi ocultado para o surgimento de uma praça durante a reforma Pereira Passos.

Atento às marcas históricas da cidade, o Executivo municipal tem dado atenção especial ao Cais do Valongo com a finalidade de assegurar sua indicação como patrimônio da humanidade. Tem, assim, contado com a cooperação do Comitê Científico Internacional do Projeto Rota do Escravo, da Organização das Nações Unidas para a Educação, a Ciência e a Cultura (Unesco). Além da Unesco, a iniciativa conta também com a participação de diferentes agentes: representantes dos governo municipal, estadual e federal, da Cdurp, de órgãos de defesa dos direitos dos negros e integrantes da comunidade, constituindo, assim, um processo bem complexo.

Segundo Dulce Vasconcellos, na época presidente do Conselho Municipal de Defesa dos Direitos do Negro da Cidade do Rio de Janeiro (Comdedine), na convocatória para a Audiência Pública sobre a criação do Circuito da Celebração Africana, resultado da descoberta do cais, foi pertinente a mobilização de organizações do Movimento Negro e órgãos públicos ligados à defesa dos direitos do negro. Foram listados a Fundação Cultural Palmares (Fcp), o Conselho Estadual do Negro (Cedine), a Superintendência de Igualdade Racial do Governo do Estado (Supir), a Coordenadoria Especial da Política de Promoção da Igualdade Racial (Ceppir) e o Conselho Municipal de Defesa dos Direitos do Negro (Comdedine) - surgidos com a redemocratização da sociedade brasileira.

0 Comdedine foi o porta-voz junto à prefeitura, tendo Eduardo Paes, então prefeito, designado Washington Fajardo, subsecretário do Patrimônio Cultural, Intervenção Urbana, Arquitetura e Design do Gabinete do Prefeito (SubPC), para cuidar do assunto. Logo houve uma reunião entre a SubPC e os conselheiros do Comdedine, dando-se início ao desenho de uma política municipal voltada ao "legado africano". Posteriormente, ocorreu uma reunião entre os integrantes da Fundação Cultural Palmares, instância federal, e os órgãos de defesa dos direitos do negro (instâncias municipal e estadual), tendo por objetivo elaborar ações pertinentes para o local. Houve ainda a reunião entre o Comdedine, a Cdurp e a Subpc, cujo resultado foi a formulação do Grupo de Trabalho Curatorial do Projeto Urbanístico, Arquitetônico e Museológico do circuito, formado por representantes da Cdurp, da prefeitura e do Comdedine, sacerdotisas das religiões afro e moradores da localidade. ${ }^{3}$ Em 29 de novembro de 2011, através do Decreto n ${ }^{\circ}$ 3.480, a prefeitura do Rio de Janeiro criou o Circuito Histórico e Arqueológico de Celebração da Herança Africana, que, conforme a imagem abaixo, é formado por diferentes lugares. ${ }^{4}$ 


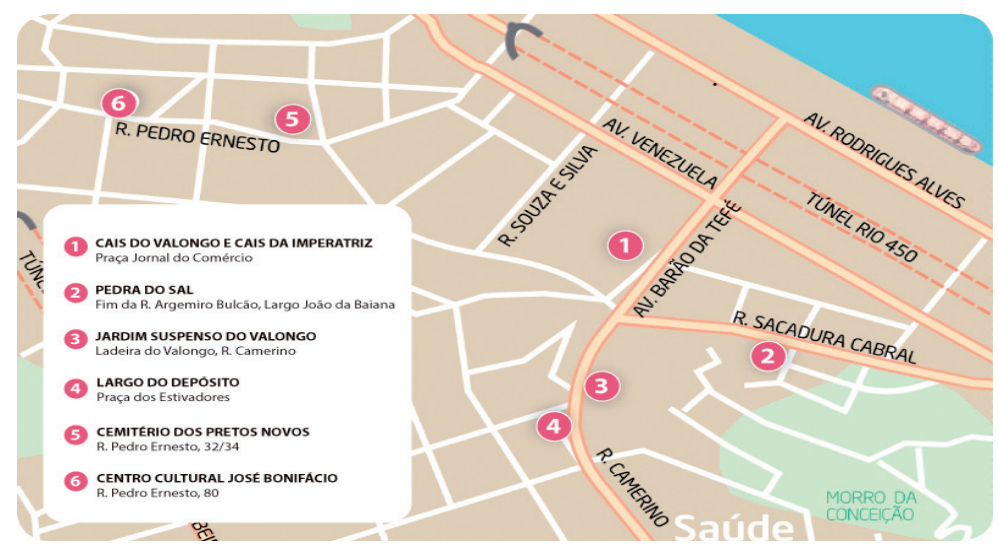

http://www.portomaravilha.com.br/circuito

Com a criação do Circuito da Celebração Africana, com espaços museais (Museu do Amanhã e Museu de Arte do Rio) e algumas edificações restauradas, a Cdurp elaborou um roteiro de "caminhada cultural" para conhecimento da região portuária. Assim, tem-se dado destaque ao compromisso do governo municipal com a "valorização do patrimônio material e imaterial da área", conforme afirma a Cdurp.5

Acompanhar a formulação do Circuito da Celebração Africana, as articulações da prefeitura com agências nacionais e internacionais para fazer do cais um patrimônio da humanidade, assim como sua inserção no roteiro de "caminhada cultural", levou-nos a indagar: em que medida a apropriação da "herança africana", construída como patrimônio, pode passar a significar mais um "bem de consumo" a ser "comercializado", conforme a lógica do mercado?

0 âmbito das políticas públicas para o patrimônio conta com uma ampla rede institucional: órgãos estatais - com inscrições nacional, estadual e municipal, agências internacionais e grupos "étnico-populares". Esse arranjo coloca duas questões: a) a vinculação entre patrimônio e sustentabilidade da comunidade, pois esta deve gerar renda com suas práticas culturais; $b$ ) a vinculação do patrimônio à economia, já que agências especializadas buscam captar e relacionar como atração aquilo que pode ser apresentado como expressão única de um modo de ser e viver (Farias, 2013). Considerando a relação entre economia e cultura, podemos entender que na ideologia de "revitalização", no Rio de Janeiro, que prevalece no discurso do governo, a política de patrimônio está menos voltada para a ideia de identidade étnico-racial e mais implicada com ações voltadas para a obtenção de recursos a partir da formação e uso do patrimônio, que passa a ser concebido como "mercadoria cultural" (Leite, 2007: 65).

Então, apesar do enaltecimento da tradição africana e da ênfase dada ao Cais do Valongo para o projeto de revitalização da cidade, a prefeitura nem sempre apoia de forma mais efetiva as 
pesquisas arqueológicas realizadas no Cemitério dos Pretos Novos e no Cais do Valongo para o "desvendamento" da história dos negros naquela região. Afirmamos isso a partir das críticas feitas por integrantes do Movimento Negro, ${ }^{6}$ cabendo, então, destacar como determinados locais foram e são construídos enquanto "legado africano". Na lógica de promoção de um produto, é assim que estamos entendendo a criação do Circuito da Celebração Africana: a categoria patrimônio tornou-se um recurso incontornável das estratégias de definição de uma imagem de marca, constituindo-se, ela própria, como a "marca" que define certo valor concorrencial e comunicacional.

Assim, embora esteja prevista a destinação de 3\% do valor da comercialização dos Cepacs para o eixo cultural do Porto Maravilha, os dados apontam para práticas que parecem fundamentais no processo de "enquadramento" (Pollak, 1992) de uma memória afrodescendente na localidade, que é consoante com a imagem de cidade que se quer produzir.

Mas existe o outro lado da patrimonialização do cais, sobretudo com a participação de setores diversificados da sociedade que, com suas leituras diferenciadas acerca do patrimônio afrodescendente da região, deixam as interpretações sempre abertas a novas possibilidades. Entendemos que os locais que compõem o Circuito da Herança Africana adquirem uma conotação política, podendo contribuir tanto para as lutas por legitimação e contra a discriminação dos que se consideram afrodescendentes, como para uma certa "folclorização", no sentido de ser transformado em atração, e domesticação de suas expressões culturais. Com isto, o "legado africano" se torna ele próprio objeto de todo tipo de disputa - econômica, política, cultural. Espaço de luta e de tensão em relação ao futuro das tradições locais, do patrimônio material e imaterial, a Zona Portuária pode ser pensada dentro de toda uma dinâmica das relações sociais que ocorrem no cotidiano da vida local, com seus múltiplos espaços de música, de dança, de religiosidade e suas múltiplas formas de sociabilidade.

A participação e a apropriação popular do patrimônio corroboram a abordagem dos locais do Circuito da Celebração Africana, sobretudo o Cais do Valongo, porque configuram um contra-uso e uma outra narrativa, como os demais patrimônios afro-brasileiros surgidos no país com a contribuição de segmentos do Movimento Negro, como o tombamento do terreiro da Casa Branca, em Salvador, e a Serra da Barriga, em Alagoas (Santos, 2005; Velho, 2006). No Rio de Janeiro, segmentos do Movimento Negro enfatizam a chegada dos africanos, a escravidão e a cultura afro-brasileira, ressaltando o Cais do Valongo. Assim, tem-se a compreensão de questões que perpassam o patrimônio, sobretudo de seu "uso social", pois que ele envolve diferentes atores interessados no presente e no passado, não sendo uma preocupação somente de especialistas (Canclini, 1997: 203).

Acreditamos que a disputa em torno do legado da cultura negra na Zona Portuária coopera para o entendimento das permanências e mudanças em torno deste tema como 
forma de resistência e de luta frente às rupturas que se enunciam, em especial num território que tem muitas histórias e tradições, e é um campo minado de memórias em disputa. A seguir contemplamos a apropriação do cais por segmentos do Movimento Negro e de membros de religiões de matriz africana.

\section{VIDAS E OBRAS DOS “ANCESTRAIS": OUTRAS VOZES E SIGNIFICADOS DADOS AO PATRIMÔNIO}

D

estacamos dois eventos que ajudam a compreender uma concepção diversa do patrimônio, que apresenta outros usos, outras vozes, sentidos e formas de interação e fruição da cidade. Por fim, esses eventos explicitam o patrimônio como lugar de luta, identidade e memória pautada no conflito e na reivindicação.

As celebrações estão relacionadas a duas figuras públicas que se iniciaram no mundo artístico como atores e contribuíram para a reflexão sobre a sociedade brasileira. As atividades desenvolvidas estão vinculadas ao reconhecimento de suas biografias, sendo uma de um ator, dramaturgo e político, e a outra de um ator e cineasta. Os eventos foram selecionados por expressarem outro uso do Circuito da Celebração Africana, especificamente do Cais do Valongo.

1) Em 14 de março de 2014, comemorou-se o centenário de nascimento do ator, dramaturgo, professor, ativista político e ex-senador Abdias do Nascimento, nome sempre lembrado em diversos segmentos do Movimento Negro no Brasil e da cidade do Rio de Janeiro por sua história de luta contra o racismo (Nascimento, 2013).

Bacharel em Ciências Econômicas e em Sociologia, Abdias fundou o Movimento Negro Unificado (MNU) no final da década de 1970, depois de ter fundado o Teatro Experimental do Negro (TEN) em 1944, movimento que buscava assegurar formação, espaço de atuação e reconhecimento para artistas negros. Em suas palavras, o TEN tinha como característica "trabalhar pela valorização social do negro no Brasil, através da educação, da cultura e da arte" (Nascimento, 2004:210). Segundo ele, o espaço teatral tinha então dois objetivos:

promover, de um lado, a denúncia dos equívocos e da alienação dos chamados estudos afro-brasileiros, e fazer com que o próprio negro tomasse consciência da situação objetiva em que se achava inserido. Tarefa difícil, quase sobre-humana, se não esquecermos a escravidão espiritual, cultural, socioeconômica e política em que foi mantido antes e depois de 1888, quando teoricamente se libertara da servidão (Nascimento, 2004: 211).

Além da encenação de diversas peças, o TEN organizou ações educativas como o I Congresso do Negro Brasileiro, em 1950, o Concurso do Cristo Negro, em 1955, e seminários com o sociólogo e político Guerreiro Ramos no Instituto Nacional do Negro (INN), voltado 
para o estudo e a pesquisa, encerrando suas atividades no final da década de 1960, em pleno regime militar (Nascimento, 2004).

A homenagem, intitulada "Os ancestrais do Valongo - Centenário de Abdias do Nascimento", foi organizada pelo Instituto de Pesquisas e Estudos Afro-Brasileiros (Ipeafro), reconhecida entidade civil aliada ao Movimento Negro fundada por Abdias do Nascimento em 1981, quando este retornou do exílio. Voltado para o ensino e pesquisa de temas afro-brasileiros, o instituto atualmente é conduzido por Elisa Larkin, sua diretora-presidente, ${ }^{7}$ viúva do artista e senador.

0 material de divulgação do evento, como pode ser visto abaixo, compreende uma foto do homenageado em um momento de discurso, estando com os braços semilevantados e os dedos indicadores em destaque. Sobre a fotografia, paira a frase: "Os ancestrais do Valongo - 100 anos de Abdias do Nascimento". Com a composição, veicula-se a figura de um homem dedicado à luta, apto a conclamar e a educar os afro-brasileiros e, ao mesmo tempo, denunciar o racismo no país.

0 ato teve a participação de políticos, como a ministra Luiza Bairros (Secretaria de Políticas de Promoção da Igualdade Racial), artistas, como Léa Garcia (antiga integrante do TEN), atletas, como o jogador Lilian Thuran (da Fondation Lilian Thuran d'Éducation contre le Racisme), acadêmicos, como Anani Dzidzienyo, Kabengele Munanga, Sueli Carneiro e Leda Maria Martins (que integraram uma mesa redonda), e autoridades religiosas, sobretudo sacerdotisas das religiões de matriz africana, como mãe Beata, mãe Edelzuíta e mãe Celina, que participaram do ritual religioso realizado naquele dia, como será visto adiante.

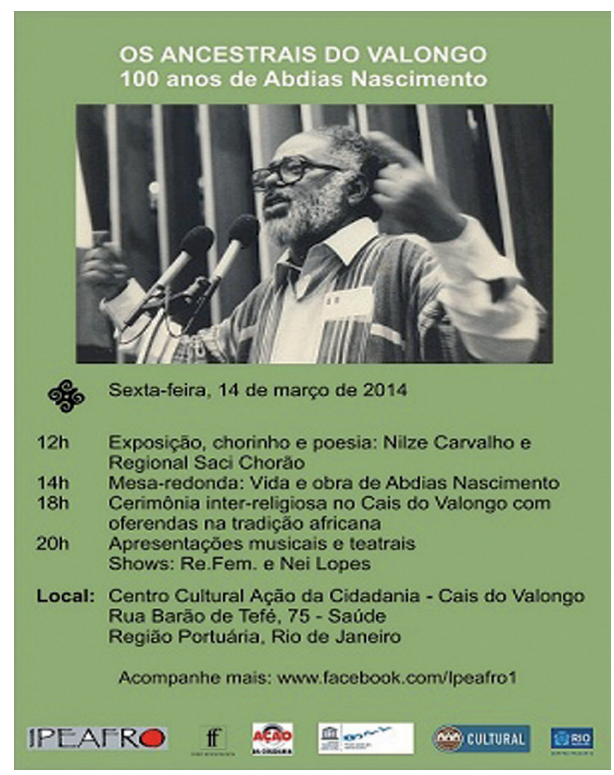

http://premioabdiasnascimento.org.br 
A cerimônia fez parte das as comemorações dos 20 anos do Projeto Rota do Escravo da Unesco e da Década Internacional dos Povos Afrodescendentes da Organização das Nações Unidas (ONU), com início em 2013 e fim previsto para 2022. A programação compreendia apresentação musical, palestras e encenações teatrais, ocorrendo as duas primeiras no Centro Cultural Ação da Cidadania (CCAC), instalado num armazém localizado na Zona Portuária em frente ao Cais do Valongo, construído em 1871 pelo abolicionista e engenheiro negro André Rebouças. 0 interior do prédio estava decorado com esculturas de madeira, exposição de livros e atividades que integraram a trajetória do homenageado.

No final da tarde, um cortejo saiu do CCAC para as ruínas do Cais do Valongo, seguido de uma encenação realizada por companhias de artes localizadas na Zona Portuária caracterizadas por lidar com diferentes linguagens e mídias para a composição e a compreensão de narrativas transmídias. 0 cortejo, intitulado "rito do nascimento", foi divulgado como homenagem a Abdias do Nascimento, e contava com figuras que remetiam ao Teatro Experimental do Negro (referência na valorização de artistas negros), à Revolta da Chibata (episódio ocorrido no início do século XX como reação às condições de trabalho que a Marinha brasileira dispensava aos marinheiros, que eram negros, mestiços, descendentes de escravos), e à cultura afro-brasileira, com menção aos orixás e às suas sagas, o que compôs o espetáculo que tomou a rua e o Cais do Valongo.

Logo depois aconteceu a cerimônia inter-religiosa com a entrada de sacerdotisas das religiões de matriz africana - mãe Beata, mãe Edelzuíta e mãe Celina. Estas estavam acompanhadas por Wande Abimbola, ex-reitor da Universidade Obafemi, por Olabiyi Yai, ex-embaixador da República do Benin e ex-presidente do Conselho Executivo da Unesco, e Elisa Larkin, viúva do homenageado. 0 grupo se posicionou nas pedras do cais e realizou a cerimônia de saudação aos orixás. Foram feitas orações e oferendas nas ruínas, nas pedras do antigo cais, para os espíritos dos milhares de africanos que foram trazidos para a realização de trabalho escravo no Brasil, conforme afirmou uma das sacerdotisas das religiões de matriz africana presentes ao ato religioso.

A cerimônia foi realizada para saudar os antepassados, ou melhor, os "ancestrais", conforme os depoimentos e materiais distribuídos. Compareceram ainda representantes de diversas tradições religiosas - católica, protestante, judaica, islâmica - e ciganos. 0 momento religioso foi realizado na área que antecede as pedras do cais, ficando o local próximo de onde permaneceram as sacerdotisas das religiões de matriz afro e os representantes dos países africanos, como relacionados acima.

A cerimônia reverenciou Abdias do Nascimento e os escritores negros Maria Carolina de Jesus e Ele Semog, conforme explicita o próprio título da celebração. Todos os homenageados foram reconhecidos como "ancestrais", sendo que as atividades ressaltavam que Abdias construíra sua biografia pautado na luta em prol dos direitos dos afro-brasileiros e contra as 
injustiças sociais (Nascimento, 2013). Os "ancestrais" seriam os africanos que chegaram ao país pelo cais e enfrentaram exploração, sofrimento, humilhação e morte, mas não deixaram de produzir expressões culturais e táticas de resistência.

2) 0 evento "Herança Africana - Intervenções Urbanas no Caminho do Porto" teve início em 2012, e, segundo Zózimo Bulbul, seu idealizador, o projeto resultou de uma ideia apresentada em evento realizado em 1978 no Museu de Arte Moderna (MAM) do Rio de Janeiro, destinado a refletir sobre os 90 anos da abolição da escravidão. ${ }^{8}$

Em 2014, o homenageado foi o próprio Zózimo, ator e cineasta falecido em janeiro do ano anterior, fundador do Centro Afro Carioca de Cinema em 2007. Trata-se de uma entidade voltada para a promoção dos artistas, da cultura afro-brasileira, para a construção e a visibilidade da memória, entre outros pontos.

0 material de divulgação do evento, como se pode ver a seguir, apresenta uma máscara posicionada acima da frase "Herança Africana: reverência a todos os africanos que por aqui passaram", de autoria do patrono da celebração. Ao observar o material, compreendemos a disposição do homenageado de provocar reflexões sobre a presença negra no país e na cidade, incluindo a ligação com a África, que buscou incentivar a partir do cinema.

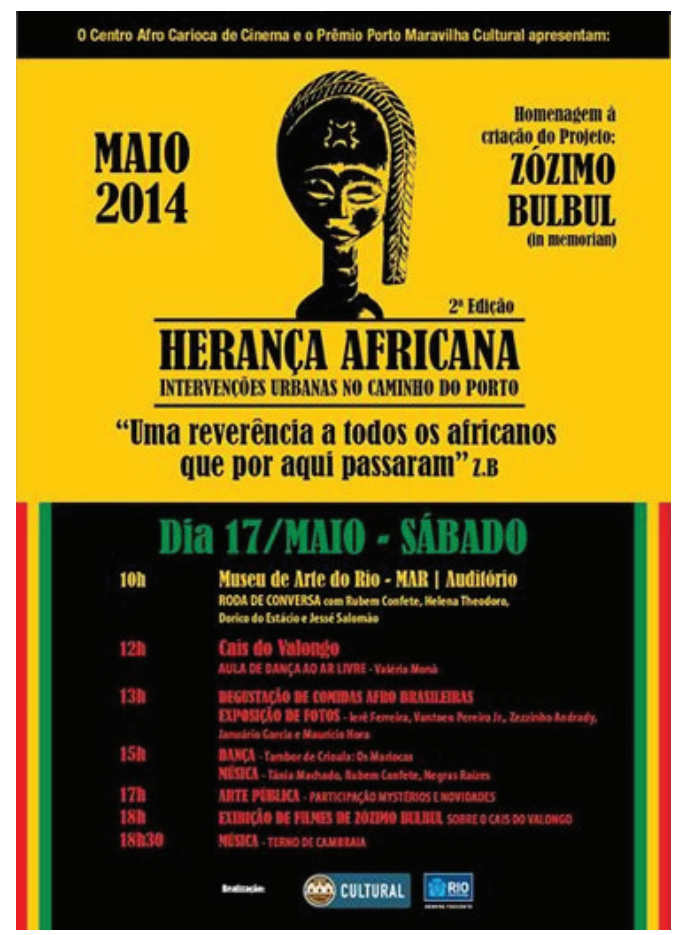

http://afrocariocadecinema.org.br 
Zózimo Bulbul foi um dos primeiros cineastas a abordar a temática racial, e os filmes que dirigiu têm por característica dar visibilidade aos artistas negros. Assim, dialogou com a concepção do Teatro Experimental do Negro (TEN), fundado por Abdias do Nascimento, atento a uma dramaturgia que não excluía a arte e os artistas negros. Para manter o objetivo do fundador, 0 Centro Afro Carioca de Cinema conduz oficinas, mostras de filmes, seminários e encontros de cinema, que confrontam a representação do negro no cinema convencional (Carvalho, 2012).

Em entrevista concedida em novembro de 2012, pouco antes do seu falecimento, Zózimo Bulbul comentou sobre o evento "Herança Africana" e a relevância do Cais do Valongo:

O Cais do Valongo tem uma importância muito grande para nós afro-brasileiros. Foi por ali que chegamos aqui. Eu posso falar com propriedade porque a África discute muito isso, a América somos nós, a América Central e a América do Sul. E nós temos que participar, olhar com calma e sabedoria para o africano presente neste continente. A simbologia de estar nestes espaços nos leva à mudança de hábitos, conceitos e subjetividades. Temos que mergulhar de forma consciente em nossa história, em nossas memórias. ${ }^{9}$

Na fala do cineasta, o cais sobressai como lugar de experiências e de referências, haja vista ser apontado como lugar da chegada e entrada de antepassados no país - fato valorizado, de forma recorrente, entre os negros integrantes de segmentos do Movimento Negro com os quais tivemos a oportunidade de conversar. Assim, o cais aparece como adequado suporte ao conhecimento, à reflexividade e às narrativas relacionadas ao passado e ao presente. Por isso, ele foi escolhido para ser o palco do evento "Herança Africana".

A edição de 2014 teve lugar de 16 a 18 de maio, sendo composta por gastronomia, música, degustação de comidas afro-brasileiras, roda de conversa, dança, cortejo, exibição de filmes sobre o Cais do Valongo e homenagem a personalidades negras. Foram "reverenciados" (conforme o folder do evento) 157 personalidades, aqueles que por meio de sua atuação nas artes, na educação, no mundo acadêmico e no conhecimento técnico e cinematográfico contribuíram ou contribuem para compor a resistência e a história de uma população. Entre outros, temos Pixinguinha, Jamelão, Cartola, Zózimo Bulbul, e intelectuais como Lélia Gonzales, Abdias do Nascimento, Joel Rufino, Machado de Assis, Lima Barreto e Joaquim Barbosa.

No primeiro dia, um cortejo saiu à noite da área da Pedra do Sal, local relevante para os afro-brasileiros, e dirigiu-se para o Cais do Valongo, num percurso de cerca de 1 quilometro, sendo conduzido por sacerdotisas das religiões de matriz africana que incensaram o caminho, e por fiéis que tocaram instrumentos e também dançaram.

0 vídeo "Cortejo da Herança Africana", editado pela Cultne, ${ }^{10}$ veicula a coreografia executada pelo bailarino Rubens Barbot diante de uma oferenda aos orixás disposta numa 
base, distante alguns centímetros do chão e forrada com toalhas brancas. Sobre ela, veem-se vasos com flores, velas e frutas, e em sua volta folhas verdes dispersas pelo chão. 0 bailarino fundou a Companhia Rubens Barbot Teatro de Dança,em 1990, no Rio de Janeiro, e com inscrições performáticas apresenta reflexões sobre o negro no Brasil, questionando desse modo o mundo da dança, que, como o cinema, costuma tornar o negro invisível (Ramalho, 2012). Sobre a celebração, no vídeo feito pelo Cultne, o bailarino Rubens Barbot observou o seguinte:

Eu acho que em realidade este ritual, que nós estamos fazendo hoje, ele já existia com o Zózimo Bulbul, com Abdias do Nascimento, com Mercedes Baptista e outros tantos que vieram antes da gente e ensinaram a gente a teimar, persistir com a nossa cultura negra... Porque para a gente 0 que nos falta é memória. 0 negro brasileiro tem muito pouca memória. A gente procura livros para saber dos nossos ancestrais e a gente não encontra. Então, eu espero que a partir daqui esta história seja escrita a respeito da nossa existência hoje não só no Rio de Janeiro como no Brasil inteiro.

Como participante da celebração, que marca o Cais do Valongo e a Pedra do Sal como patrimônio afro-brasileiro, e enquanto bailarino, que expressa com a dança uma leitura acerca da existência de afro-brasileiros, Rubens Barbot destacou alguns nomes-chave para os militantes e para o fortalecimento da história dos negros no Brasil, bem como sua presença e persistência em constituir espaços relacionados com a cultura afro-brasileira. Ele enfatizou ainda as práticas públicas como condição de composição e visibilidade de uma memória, que, para ele, não tem sido comunicada, mas sim ignorada e, por isso, está ausente dos livros. A memória a ser destacada compreende conhecimentos, fazeres e lugares relacionados às experiências e vivências dos negros, que devem estar nas áreas públicas e nos instrumentos de saber, como os livros. Por isso, Barbot questionou a sociedade brasileira pelo trabalho de seleção de elementos voltados para compor uma memória excludente - ou a "história", como dizia Zózimo Bulbul -, evidenciando que memórias são forjadas por hierarquizações, controles, exclusão de questões, eventos, atores, lugares, conhecimentos e experiências.

\section{PARA FECHAR: MEMÓRIA, CONFLITO E LIGAÇÃO ENTRE VIVOS E "ANCESTRAIS"}

E m uma leitura mais apressada, poderíamos dizer que a prática de revitalização efetivada pela prefeitura do Rio de Janeiro no contexto do projeto Porto Maravilha pode ser entendida como diferente daquelas que ocultaram e expulsaram espaços considerados ligados à escravidão e à população negra, bem como suas vivências culturais. Contudo, não podemos 
nos enganar, pois, como vimos, existem tensões e negociações constantes na região objeto do projeto de revitalização.

Alguns lugares e ruínas revestem-se de significados e integram a construção de patrimônios e memórias passíveis de contribuir para a alteração simbólica da cidade, compondo sua singularidade como adequada ao interesse turístico, à especulação imobiliária e à obtenção de recursos (Gonçalves, 2013; Leite, 2007). Os documentos da Cdurp nos colocam diante de um trabalho de justificação que passa a orientar a seleção de elementos concebidos como referidos ao "passado", à escravidão. É afirmado o compromisso com o não "esquecimento", o não "ocultamento", como aconteceu no passado com o Cais do Valongo, por testemunhar um passado a ser esquecido. Contudo, observa-se que as ações daqueles encarregados da revitalização da Zona Portuária estão voltadas menos para a inclusão social e o atendimento das demandas por igualdade, e mais para o projeto de revitalização e seu "roteiro de visitas", condizentes com a busca por recursos econômicos para a cidade.

Outro uso do Cais do Valongo é feito por integrantes de segmentos do Movimento Negro e membros de religiões de matriz africana, sendo demarcado com as celebrações que combinam religião, política e arte. Há que ser dito que práticas culturais afro-brasileiras integram o acervo cultural brasileiro, contando festividades laicas e religiosas. Entendemos que as celebrações não podem ser tomadas somente como parte da composição de uma imagem viável ao consumo, como os estudos sobre o patrimônio apontam, porém cooperam para singularizar um espaço urbano mediante os corpos que se expõem, resistem e inscrevem questionamentos e dissensos (Jacques, 2010). Isso ocorre precisamente com a referência aos "ancestrais", evidenciando a validade do patrimônio também para aqueles que ressaltam o pertencimento racial.

As apropriações e os modos de relação com o "passado", ou com os passados, acontecem, e estes podem ser formulados e mobilizados diferentemente. Isso foi apontado quando foram focalizados o projeto de revitalização e os agentes que o efetivam, conduzem e lidam com o patrimônio. Mas não é possível ignorar a presença e o que fazem os segmentos do Movimento Negro e os adeptos de religiões de matriz africana, pois quando estes recordam - o quê e como o fazem -, integram fazeres que evidenciam tensões na concepção e relação com o patrimônio, bem como o conflito de memórias, haja vista que isso implica a visibilidade daquilo que é ocultado pela trama da revitalização urbana.

O conflito de memória tem a ver com a visibilidade de narrativa nem sempre comprometida ou representativa dos grupos e ações que circulam em uma sociedade. Isso viabiliza indagar sobre as articulações entre patrimônio, identidade e política que pautam as diferentes narrativas sobre o passado. Muitas delas emergem com as transições políticas, entendendo que em certos regimes a esfera pública pode ser definida por controle e imposição de uma 
narrativa. Considerando os processos sociais e as lutas políticas, sobretudo na configuração democrática, aparecem disputas entre vários atores acerca dos sentidos pertinentes ao passado, que não ignoram suas experiências, inserções políticas e identidades, fazendo do "passado" um recurso retórico viável para a mobilização política (Macé, 2012).

Ao contemplar as diferentes experiências de afro-brasileiros no Cais do Valongo e adjacências, constatamos narrativas que mobilizam significantes como "passado", "África" e "memória", que são relacionados aos citados lugares que perfazem esse patrimônio. Diante da afirmativa de o Brasil ser um "país sem memória", pode-se considerar outra narrativa acerca do "passado", e para tanto o cais é adequado, não somente por representar a escravidão, mas por inseri-la num determinado momento histórico que não deve ser esquecido. A narrativa compreende a relação entre vivos e mortos, as biografias destes, as interpretações dos viventes acerca das situações experimentadas, as estéticas e as sociabilidades praticadas em áreas públicas como testemunho da existência e da visibilidade. Tornar algo visível pode ser um fazer que não exclua os mortos, o mundo espiritual e o tempo mítico - não endossando, assim, uma memória definida pelo tempo linear -, base do binômio ordem/progresso (Rocha e Eckert, 2005).

As religiões de matriz africana têm contribuído para que haja no Brasil a continuidade da concepção do tempo cíclico, diferente daquele estabelecido pela história, e com implicações para a relação com os mortos, que não estão separados do mundo dos vivos. A condição de "ancestral", enfatizada no Cais do Valongo por segmentos do Movimento Negro e membros de religiões de matriz africana, é alcançada por aquele cujo feito integra a comunidade mais ampla e forma sua memória. Isso ocorre porque ele não precisa mais renascer e não há o comprometimento com o "ciclo da eternidade", pois como antepassado ele passa a integrar o mundo dos orixás ("Orum") e pode também atuar e alterar o mundo dos vivos ("Aiyê"), bem como se fazer presente nas celebrações realizadas (Prandi, 2001).

As celebrações contempladas expressam experiências, representações dos grupos e suas lutas por direito, afirmação social e inscrição de memória. Isso pode ser mais bem compreendido quando contemplamos as falas, cânticos, ritmos e danças que compõem modos de inscrever os corpos no patrimônio, tornando-os parte deste, e assim construímos novos sentidos sobre ele. Tudo isso também forja um espaço público caracterizado pela convivência não restrita aos vivos, de percepção, como parte da ação política. Esta, por sua vez, é marcada pela "memória performática" das religiões de matriz africana, que é constituída pelo "corpo que dança, vocaliza, performa, grafa, escreve" (Martins, 2007: 81).

Para finalizar, os segmentos do Movimento Negro e os membros das religiões de matriz africana, ao ocupar e se colocar nos espaços públicos, acabam delineando o patrimônio como algo denso com suas presenças e reflexões. Pois os usos ou contra-usos que fazem 
desses espaços expressam suas reivindicações e modos de interação com os viventes e com os antepassados. Assim, esses atores narram as experiências cotidianas, religiosas, artísticas e políticas que nomeiam como memórias. Estas podem ser compostas pelo traço conflitivo, haja vista a denúncia e a reivindicação que as caracterizam e colocam em tensão a concepção da prefeitura em relacionar patrimônio e memória como meros elementos de incremento da política de revitalização da cidade.

\section{NotAs}

1 Há ainda no local a presença da comunidade quilombola Pedra do Sal, que afirma descender dos antigos escravos que ocuparam a região, em conflito com a Venerável Ordem Terceira de São Francisco da Penitência (VOT), que se apresenta como proprietária de imóveis da área. As tensões tiveram início no final dos anos 1990, observando-se a resistência de antigos moradores quilombolas.

2 Em maio de 2013 foi lançado o Dossiê do Comitê Popular da Copa e Olimpíadas do Rio de Janeiro, que denuncia e expõe as diversas violações de direitos que vêm sendo praticadas em nome dos megaeventos no Rio de Janeiro. Diferentes movimentos sociais, formados por atingidos pelas ações arbitrárias da prefeitura, estão em mobilização para resistir aos processos de "mercantilização da cidade".

3 "Audiência Pública - Cais do Valongo - 26.06.2012, às 18h - Galpão Ação da Cidadania". Disponível em: http://comdedinerj.blogspot.com.br/2012/06/audiencia-publica-cais-do-valongo.html. Acesso em 20 out. 2015.

40 Circuito da Celebração Africana conta com o Cais do Valongo; a Pedra do Sal, onde os escravos faziam 0 descarregamento de mercadoria; o Jardim Suspenso do Valongo, construído na reforma Pereira Passos; o Largo do Depósito, destinado à guarda dos africanos desembarcados; o Cemitério dos Pretos Novos, destinado ao sepultamento dos africanos mortos, e o Centro Cultural José Bonifácio, edificação construída durante o Império, e onde desde 1994 funciona o Centro de Referência da Memória Afro-Brasileira.

5 Cdurp. "Apresentação da operação urbana". Disponivel em: http://www.portomaravilha.com.br/portomaravilha. Acesso em 15 dez. 2015.

6 Uma dessas críticas dirigiu-se à inclusão no Circuito da Herança Africana do Jardim Suspenso do Valongo, que foi fruto da reforma promovida pelo prefeito Pereira Passos (1902-1906) e foi ornado com as estátuas que ficavam no antigo Cais da Imperatriz. 0 tombamento foi realizado pelo Serviço de Patrimônio Histórico e Artístico Nacional (SPHAN) em 1938. Para alguns segmentos do movimento negro, o Jardim representa a história do ponto de vista do colonizador, "dos brancos".

7 Ver: http://ipeafro.org.br/ipeafro/historico/. Acesso em 25 jan. 2016.

8 Centro Afro Carioca de Cinema. Zózimo Sempre. Informe n.05, 2013. Acesso em 25 jan. 2016.

9 Entrevista concedida ao Observatório de Favelas, entidade criada em 2001 voltada para a pesquisa e propostas de políticas públicas para as favelas. Disponível em: http://of.org.br/noticias-analises/um-convite-a-africanidade/, acesso em 21 nov. 2015.

10 Trata-se de um site que hospeda produções de vídeos feitas por artistas negros, explicitando a utilização da tecnologia na composição de um olhar forjado por afro-brasileiros sobre suas táticas políticas e culturais. 0 vídeo Cortejo da Herança Africana, 2014, está disponível em: https://www.youtube.com/watch?v=ZAX24_ iU3q8. Acesso em 11 dez. 2015. 


\section{REFERÊNCIAS BIBLIOGRÁFICAS}

ARANTES, Otília. Uma estratégia fatal: a cultura nas novas gestões urbanas. In: ——; VAINER, Carlos; MARICATO, Hermínia (Orgs). A cidade do pensamento único: desmanchando consensos. Petrópolis: Vozes, 2002. BRUGUGNOLI, Verônica F. Opções reais, operações urbanas e o mercado imobiliário na cidade de São Paulo. Tese (doutorado) Escola de Administração de Empresas de São Paulo, 2012.

CANCLINI, Néstor. Los usos sociales del patrimonio cultural. In: AGUILAR CRIADO, Encarnación (Org.). Patrimonio etnológico. Nuevas perspectivas de estudio. Junta de Andalucía: Consejería de Cultura, 1999.

. Culturas híbridas: estratégias para entrar e sair da modernidade. São Paulo: Editora da Universidade de São Paulo, 1997.

CARVALHO, Noel dos Santos. Cinegritude: reflexões sobre a invisibilidade da produção cinematográfica afrobrasileira contemporânea. In: XV Encontro Regional de História da Associação Nacional de História (ANPUH), 1, 2012. Disponível em: http://www.encontro2012.rj.anpuh.org/resources/anais/15/1338316130_ARQUIVO_ArtigoAnpuh.pdf. Acesso em 10 out.2015.

CDURP. Editorial. Revista Porto Maravilha, Rio de Janeiro, n. 4: 03, 2011. Disponível em: http://portomaravilha. com.br/revista/cod/5\#page/1. Acesso em 10 out. 2015.

FARIAS, Edson.Estado e diversidade cultural no Brasil, a partir das agendas de cultura e desenvolvimento. IV Seminário Internacional - Políticas Culturais, Rio de Janeiro, 2013. Disponível em http://culturadigital.br/ politicaculturalcasaderuibarbosa/files/2013/11/Edson-Farias.pdf. Acesso em 12 mar. 2016.

FERREIRA, João Sette W.; FIX, Mariana. A urbanização e o falso milagre da CEPAC. 2001. Disponível em http:// www.usp.br/fau/depprojeto/labhab/biblioteca/textos/ferreira_cepacfalsomilagre.pdf. Acesso em 12 mar. 2016.

FRUGOLI JR., Heitor; TALHARI, Júlio César. Entre o tecido físico e o social das cidades, entrevista com Sharon Zukin. Revista Brasileira de Ciências Sociais, São Paulo, v.29, n.84.

GIACOMET, Luciane. Revitalização portuária: caso Puerto Madero. Dissertação (Mestrado em Arquitetura), Universidade Federal do Rio Grande do Sul, Porto Alegre, 2008.

GONÇALVES, José Reginaldo $S$. The dark side of the moon: heritage, memory and place in Rio de Janeiro, Brazil. Vibrant, Brasília, n. 10, v. 1, 2013. Disponível em: http://www.vibrant.org.br/downloads/v10n1_goncalves. pdf. Acesso em 27 jan.2016.

HONORATO, Cezar. Porto do Rio de Janeiro: entre o passado e o futuro. In: SANTOS, Flávio Gonçalves dos (org.). Portos e cidades: movimentos portuários, Atlântico e diáspora africana. Ilhéus: Editus, 2011. pp.123-143.

JACQUES, Paola Berenstein. Zonas de tensão: em busca de micro-resistências urbanas. In: JACQUES, Paola Berenstein; BRITTO, Fabiana Dultra (Orgs.). Corpocidade: debates, ações e articulações. Salvador: EDUFBA, 2010.

LEITE, Rogério Proença. Contra-usos da cidade: lugares e espaço público na experiência urbana contemporânea. Campinas: Editora da Unicamp; Aracaju: Editora UFS, 2007.

—_ PEIXOTO, Paulo. Políticas urbanas de patrimonialização e contrarrevanchismo: o Recife Antigo e a Zona Histórica da Cidade do Porto. Cadernos Metrópole, São Paulo, n. 21, 2009. Disponível em: http://www. cadernosmetropole.net/download/cm/cm21.pdf. Acesso em 12 dez. 2015.

MACÉ, Jean François. Introduction à une anthropologie des conflits de memóire: une approche comparative de cas espagnol et chilien. Revue Intenationale d'Anthropologie Culturelle et Sociale, Paris, n. 1, 2012.

MARTINS, Leda, A fina lâmina da palavra. O Eixo e a Roda: revista de literatura brasileira, Belo Horizonte, v. 15, 2007. 
MATTOS, Hebe; ABREU, Regina. Relatório histórico-antropológico sobre o quilombo Pedra do Sal em torno do samba, do santo e do porto. Relatório Técnico de identificação e delimitação da comunidade remanescente de quilombo Pedra do Sal. Rio de Janeiro: MDA/Incra, 2007.

NASCIMENTO, Abdias do. Teatro Experimental do Negro: trajetória e reflexões. Estudos Avançados, Rio de Janeiro, 18(50), 2004. Disponível em: http://www.scielo.br/pdf/ea/v18n50/a19v1850.pdf. Acesso em: 11 dez.2015.

NASCIMENTO, Elisa Larkin. Abdias do Nascimento e as ações afirmativas. Terceiro Milênio: Revista Crítica de Sociologia e Política, Campos dos Goytacazes, ano 1, nº 1, 2013.

POLLAK, Michel. Memória e identidade social. Estudos Históricos, Rio de Janeiro, vol. 5, n. 10, 1992. Disponível em: http://bibliotecadigital.fgv.br/ojs/index.php/reh/article/view/1941/1080. Acesso em: 10 dez. 2015.

PRANDI, Reginaldo. 0 candomblé e o tempo: concepções de tempo, saber e autoridade da África para as religiões afro-brasileiras. Revista Brasileira de Ciências Sociais, São Paulo, vol. 16, n. 47, 2001.

RAMALHO, Cláudia. Dançologia negra carioca: cia Rubens Barbot teatro de dança 21 anos, 2012. Disponível em https://www.academia.edu/7378055/DAN\%C3\%870LOGIA_NEGRA_CARIOCA_por_Cau_RamaIho_2012_artigo. Acesso em: 09 set. 2015.

ROCHA, Ana Luiza Carvalho da; ECKERT, Cornelia. O tempo e a cidade. Porto Alegre: Editora da UFRGS, 2005.

SANTOS, Jocélio Teles dos. O poder da cultura e a cultura no poder. a disputa simbólica da herança cultural negra no Brasil [online]. Salvador: EDFBA, 2005.

SPHAN. Morro da Conceição, Rio - SPHAN protege área histórica e planeja sua revitalização. SPHAN Pró-Memória, n. 26, 1983. Disponível em http://docvirt.no-ip.com/docreader.net/DocReader.aspx?bib=BOL_ SPHAN\&PagFis=598\&Pesq=. Acesso em: 10 nov. 2015.

VELHO, Gilberto. Patrimônio, negociação e conflito. Mana, Rio de Janeiro, v. 12, n. 1, 2006. Disponível em: http://www.scielo.br/pdf/mana/v12n1/a09v12n1.pdf. Acesso em: 10 dez.2015.

YABETA, Daniela, GOMES, Flávio. Memória, cidadania e direitos de comunidades remanescentes (em torno de um documento da história dos quilombolas da Marambaia). Revista Afro-Ásia, Salvador, nº 47, 2013.

\section{VÍDEOS}

Cultne. Cortejo da Herança Africana, 2014. Disponível em: https://www.youtube.com/watch?v=zAX24_ iU3q8. Acesso em 10 dez.2015.

\section{Sites Consultados}

http://afrocariocadecinema.org.br https://blogportomaravilha.wordpress.com

http://comdedinerj.blogspot.com.br

http://www.cultne.com.br/

http://www.ipeafro.org.br

http://of.org.br/

http://www.portomaravilha.com.br/circuito

http://www.portonovosa.com

http://premioabdiasnascimento.org.br 